\title{
Role of osmotic stress and amino acid deprivation in Paracoccidioides brasiliensis dimorphism
}

\author{
Ludmilla HS Queiroz, Valeria F Tavares and Viviane S Alves* \\ Departamento de Microbiologia, Instituto de Ciências Biológicas, Universidade Federal de Minas Gerais, Brazil
}

\begin{abstract}
Paracoccidioidomycosis (PCM) is the most important systemic mycosis in South America, causing many deaths in the countries where it occurs. The disease is caused by the thermo-dimorphic fungi Paracoccidioides brasiliensis and Paracoccidiodes Lutzii, found in nature under a mycelial form (M) and as a yeast (Y) in host tissues. Transition between these two forms depends on the growth temperature, being $\mathrm{M}$ at $25^{\circ} \mathrm{C}$ and yeast at $37^{\circ} \mathrm{C}$. This work aimed to evaluate the effect of osmotic stress, lack of glucose and amino acid deficiency in P. brasiliensis dimorphism. Here we show that yeast to mycelium transition is inhibited, at room temperature, during osmotic stress and amino acid deprivation conditions, but fungal cells maintain its growth rate and viability. Our data add to extensive available literature indicating that P. brasiliensis dimorphism does not depends exclusively on growth temperature, and its morphogenesis can be influenced by multiple factors.
\end{abstract}

\section{Introduction}

Paracoccidioides brasiliensis was isolated for the first time in 1908, by Adolfo Lutz, and is the etiologic agent of paracoccidioidomycosis (PCM), the more prevalent systemic mycosis in Latin America, characterized by chronic granulomatous lesions $[1,2]$. The disease is caused by the thermo-dimorphic fungi Paracoccidioides brasiliensis and Paracoccidiodes Lutzii [3]. In nature, these pathogens are found as mycelium but its ecological niche is not yet completely clear $[4,5]$. Under adverse conditions (humidity and nutrient decrease) these fungi produce conidia, which can infect human host causing mild to severe disease [6].

P. brasiliensis is a dimorphic fungi that grows slowly as mycelium (M) at room temperature, between $23^{\circ} \mathrm{C}$ and $28^{\circ} \mathrm{C}$, and convert to yeast form (Y) between 35 and $37^{\circ} \mathrm{C}$, in vitro and at infected tissues. Mycelial colonies are small, irregular and formed by thin hyphae. Yeast colonies contain spherical or oval cells, multiplying by bi-polar or multipolar budding [4]. Morphological transition in this fungus, $M$ form to $Y$ form, is an essential step to successful establishment of infection and is primarily dependent on surrounding temperature [7-10].

Dimorphism is an adaptation process to environmental changes, observed in several pathogenic fungi [11], and involves the transformation of filamentous cells (hyphae or pseudo-hyphae) in yeast cells and vice-versa. In dimorphic fungi, temperature is the main morphological switch inducer [12] and is essential to pathogenicity [11]. In this study, we aimed to evaluate the role of osmotic and nutritional stress (absence of glucose or amino acids) on Paracoccidioides brasiliensis dimorphism.

\section{Material and methods}

\section{P. brasiliensis strain}

The P. brasiliensis was maintained in Yeast Peptone Dextrose YPD solid media (1\% yeast extract, $2 \%$ peptone; $2 \%$ dextrose $2 \%$ (pH $6.3)$ ), at $25^{\circ} \mathrm{C}$ for the mycelial form and at $37^{\circ} \mathrm{C}$ for yeast.

\section{Osmotic and nutritional stresses}

$\mathrm{Pb} 18$ isolate was grown in YPD liquid medium under constant agitation at $37^{\circ} \mathrm{C}$. After reaching $\mathrm{OD}_{600}=0.5$, cells were centrifuged at 4,000 rpm during $10 \mathrm{~min}$ at RT, culture media was removed, and cells were washed with sterile PBS. Cells were then added to SD (Synthetic Defined) liquid media (YNB - Yeast Nitrogen Base - Difco plus $2 \%$ glucose), supplemented or not, with $\mathrm{NaCl}$ (Sigma) at different concentrations $(250 \mathrm{mM}, 500 \mathrm{mM}$ and $1 \mathrm{M})$. Alternatively, osmotic stress was performed using $1 \mathrm{M} \mathrm{KCl} \mathrm{(Sigma)} \mathrm{or} \mathrm{1M} \mathrm{Sorbitol} \mathrm{(Sigma)} \mathrm{in}$ SD. Yeast cells suspended in the indicated media $(2 \mathrm{~mL})$ were added to 24 wells plates and incubated at $25^{\circ} \mathrm{C}$ to analyze $\mathrm{Y}$ to $\mathrm{M}$ conversion or added to 96 well plate to other analysis. For glucose deprivation experiments, we used SD liquid media without glucose (S media or S(-dex)), and for amino acid starvation SD was prepared with YNB without amino acids and ammonium sulfate (Difco).

\section{Growth and dimorphism analysis}

$P$. brasiliensis growth and dimorphism was evaluated during 11 days by microscopic observation, with periodic inspection of cells stained with lactophenol cotton blue. Fungal growth rate was determined by measuring the cell density at $600 \mathrm{~nm}$ on 96 well plate.

\section{Cell viability}

To determine the yeast cells viability we measured the metabolic activity by using MTT assay. Twelve days after stress exposure, cell suspension $(100 \mathrm{uL})$ from each tested well in a 24 wells plates were

${ }^{\star}$ Correspondence to: Viviane S. Alves, Departamento de Microbiologia, Universidade Federal de Minas Gerais, Av Antonio Carlos, 6627, ICB,Bloco F4 - 171, Laboratorio de Biologia Celular de Microrganismos, Brazil, Tel: +55 31 3409-3018, Fax: +55 31 3409-2733, E-mail: gouveiava@ufmg.br

Key words: Paracoccidioides brasiliensis, dimorphism, osmotic stress, amino acid deprivation

Received: May 22, 2018; Accepted: June 12, 2018; Published: June 15, 2018 
removed and added to a 96 well plate. MTT (3-(4,5-Dimethylthiazol2-yl)-2,5-Diphenyltetrazolium Bromide - Sigma) $0.5 \mathrm{mg} / \mathrm{mL}$ (final concentration) was added to each well and plate was incubated during 18h. After incubation, the medium containing MTT was removed, and dimethyl sulfoxide $(100 \mu \mathrm{L})$ was added to solubilize the MTT formazan product. MTT formazan formation was measured at $490 \mathrm{~nm}$. Background formazan values were determined using wells containing media (SD, SD $+\mathrm{NaCl}, \mathrm{S}$ or SD w/o aa) and MTT. Data were analyzed employing Two-Way ANOVA and Bonferroni post-test.

\section{Results and discussion}

Extensive studies on P. brasiliensis and other dimorphic fungi has demonstrated that morphological transition between $\mathrm{M}$ and $\mathrm{Y}$ phases is an essential step to successful infection establishment, and is triggered by temperature changes, from $25^{\circ} \mathrm{C}$ to $37^{\circ} \mathrm{C}$ [7-9]. Here we show that $1 \mathrm{M} \mathrm{NaCl}$ block P. brasiliensis hyphae formation at $25^{\circ} \mathrm{C}$, when compared to the same cells incubated in $\mathrm{SD}$ without $\mathrm{NaCl}$ (Figure 1). We aimed to verify the minimum $\mathrm{NaCl}$ concentration of which inhibits $\mathrm{Y}$ to $\mathrm{M}$ conversion and as showed in figure 2 we demonstrate that dimorphism inhibition also occurs in the presence of reduced $\mathrm{NaCl}$ concentrations $(250 \mathrm{mM}$ and $500 \mathrm{mM})$, however in these conditions we were able to see some hyphae, 11 days after our analysis start point. In accordance to our findings, previous work has shown that $\mathrm{Na}^{+}$ions influence Candida albicans dimorphism, inhibiting germinative tube formation [13]. Considering these findings, we asked about if this P. brasiliensis osmotic response is specific to $\mathrm{Na}^{+}$ions and, as shown in figure 2, dimorphic transition was also inhibited by $1 \mathrm{M} \mathrm{KCl}$ and $1 \mathrm{M}$ Sorbitol, at room temperature. These data corroborate a previous study demonstrating that $0.3 \mathrm{M} \mathrm{NaCl}$ and $2 \%$ Sorbitol inhibits its growth rate, and reinforces many findings suggesting that $P$. brasiliensis dimorphism is not exclusively triggered by thermal conditions [10].

Since osmotic environment is important to dimorphic switch in $P$. brasiliensis, we hypothesized that other stressors can act as dimorphism influencers. The yeast cells were then subjected to the glucose starvation ( $\mathrm{S}$ media) but we do not notice any change in dimorphic transition in this condition. In contrary, amino acids deprivation (SD w/o aa) resulted in $\mathrm{Y}$ to $\mathrm{M}$ conversion inhibition, at room temperature, but we still observe some cells initiating transition suggesting that amino acids absence result in delayed transition (Figure 3).

Our observations on dimorphism inhibition could result from reduced $P$. brasiliensis viability upon stress, but this was not the case, since $\mathrm{Pb} 18$ cells density during osmotic and nutritional stress increased (Figure 4A), indicating an active metabolism. Contrasting,

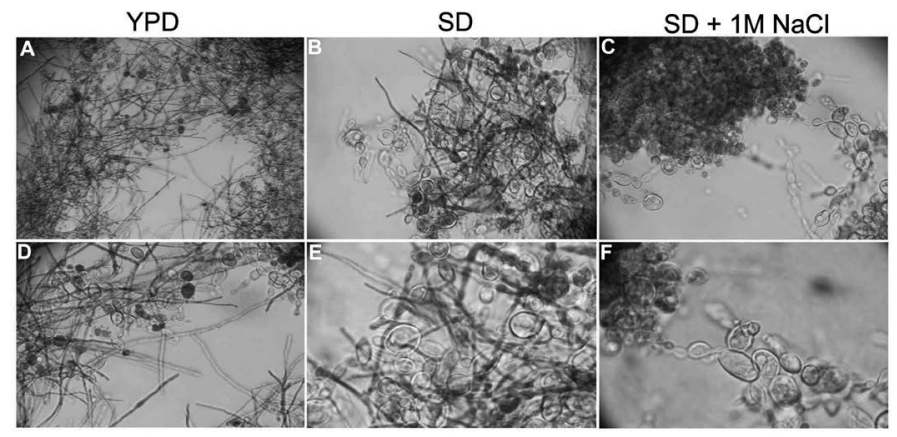

Figure 1. Osmotic stress induced by $\mathrm{NaCl}$ blocks $P$. brasiliensis conversion from $\mathrm{Y}$ to $\mathrm{M}$ form. $P$. brasiliensis yeast cells convert from $\mathrm{Y}$ to $\mathrm{M}$ form four days after experiment start in YPD and SD media (A, B, D and E) but this conversion is blocked in SD supplemented with $1 \mathrm{M} \mathrm{NaCl}(\mathrm{SD}+\mathrm{NaCl}-\mathrm{C}$ and $\mathrm{F})$. The assay was repeated independently more than 5 times. A - 10X magnification; B, C and D - 40X magnification. E and F - 100X magnification.

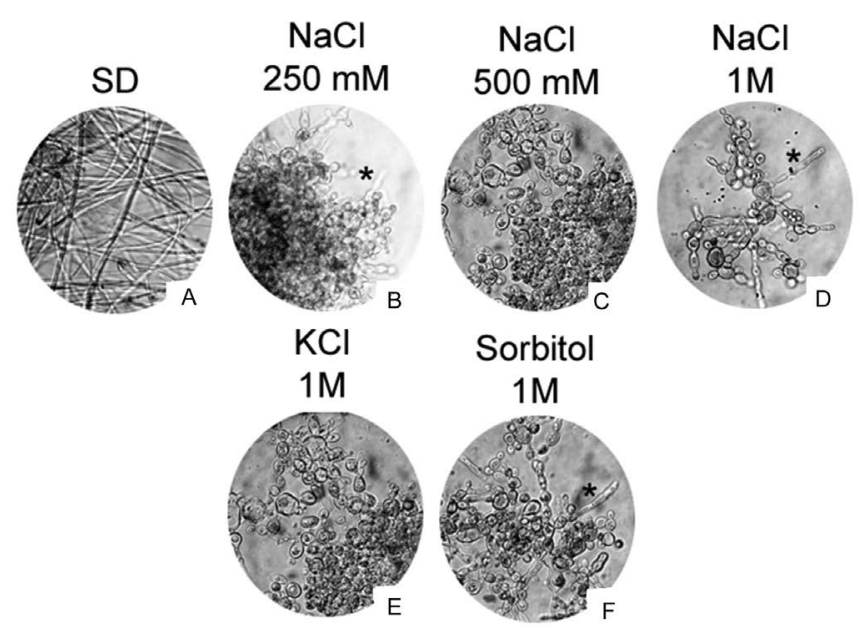

Figure 2. Osmotic stress induced by different $\mathrm{NaCl}$ concentrations, as well as $\mathrm{KCl}$ and Sorbitol, blocks $\boldsymbol{P}$. brasiliensis dimorphism. $P$. brasiliensis yeast cells grown in the presence of $250 \mathrm{mM}$ or $500 \mathrm{mM} \mathrm{NaCl}$ does not convert efficiently from $\mathrm{Y}$ to $\mathrm{M}$ (B and $\mathrm{C}$ ), as occur in the presence of $1 \mathrm{M} \mathrm{NaCl}(\mathrm{D}), 1 \mathrm{M} \mathrm{KCl}(\mathrm{E})$ or $1 \mathrm{M}$ sorbitol (F), when compared to the same cells grown in SD media (A). Asterisks in B, D and F indicates some yeast cells at initial steps to $\mathrm{M}$ form trasition. The assay was repeated independently more than 5 times. $40 \mathrm{X}$ magnification

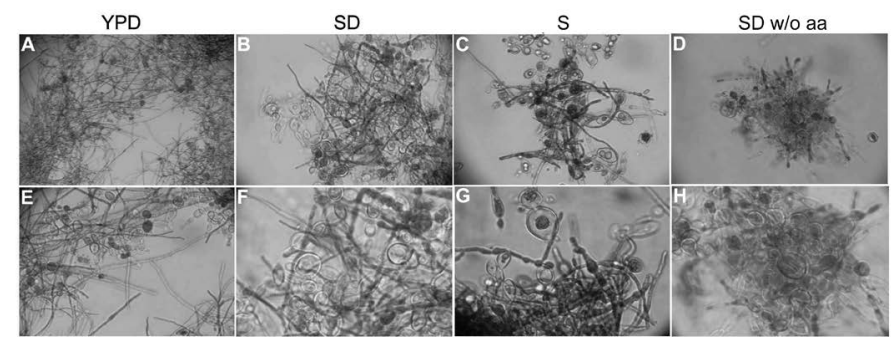

Figure 3. Amino acid starvation inhibit $\boldsymbol{P}$. brasiliensis dimorphism. $P$. brasiliensis yeast cells grown on minimal media without without amino acids (SD w/o aa) showed inhibition of conversion from $\mathrm{Y}$ to $\mathrm{M}$ form, when compared to the same cells grown in YPD, SD ou $\mathrm{SD}$ media without glucose $(\mathrm{S})$. The assay was repeated independently more than 5 times. A - 10X magnification; B, C, D and E-40X magnification; F, G and H -100X magnification.

only cells submitted to amino acid deprivation showed reduced growth rate when compared to the other stress conditions, stopping cellular multiplication 2 days after analysis start point (Figure 4A). The reduced growth of amino acid deprived $P$. brasiliensis indicates that amino acids are essential to fungal growth, and dimorphic switch as showed in figure 3. The metabolic activity in stressed P. brasiliensis was also measured by MTT assay, 12 days after stress start point. Using this approach, we were able to confirm that $P$. brasiliensis cells were viable during the analyzed time points (Figure 4B). It is important to note, that the observed growth and cellular viability during stress conditions can result from metabolic utilization of stored nutrients, acquired by $P$. brasiliensis cells during the initial growth in YPD, just before the conversion assay start point; therefore, yeast cells were able to maintain cellular homeostasis during analyzed period.

Here we demonstrate that $P$. brasiliensis dimorphism is not exclusively triggered by temperature, since osmotic stress induced by different concentrations of $\mathrm{NaCl}, \mathrm{KCl}$ and Sorbitol, as well as the lack of amino acids, are able to inhibit morphogenesis, blocking yeast to mycelium transition, as previously suggested by Cano and Vidal [14].

\section{Conclusion}

We show that $P$. brasiliensis dimorphism does not depends solely on temperature as other environmental factors, such as the osmotic 
A

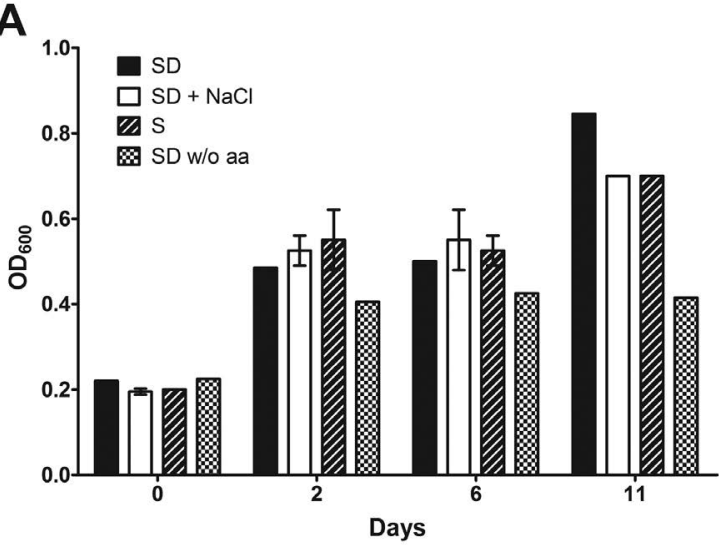

B

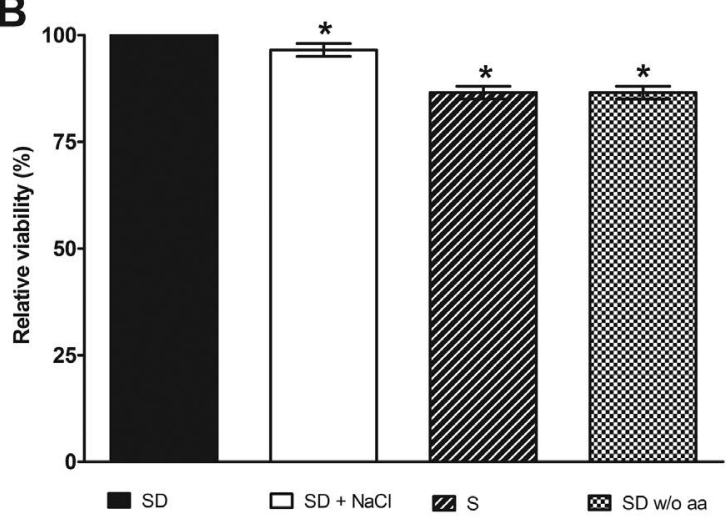

Figure 4. P. brasiliensis growth and viability is preserved upon osmotic and nutritiona stress. A) $P$. brasiliensis growth was evaluated during stress $(1 \mathrm{M} \mathrm{NaCl}$, glucose and amino acids deprivation) by spectrophotometric measurement at $\mathrm{OD}_{60}$, showing that cells have normal growth during tested conditions. B) P. brasiliensis metabolic activity was assessed quantitatively using MTT reduction assay and we observed a little decrease in viability upon stress, being most cells still viable. Metabolic activity in SD media was taken as $100 \%$. Results shown were the average of three independent experiments \pm SD. ${ }^{*} p<0.05$ when compared with SD media.

environment, glucose and amino acids availability, are essential to dimorphic transition and potentially pivotal to infection establishment. The molecular processes underlying our findings are subject of future work.

\section{Acknowledgements}

We thank Dr. Patricia S. Cisalpino by P. brasiliensis $\mathrm{Pb} 18$ strain and PRPq-UFMG (Pro-reitoria de Pesquisa da Universidade Federal de Minas Gerais) for support.

\section{Author contributions}

VSA conceived and designed the experiments. LHSQ, VFT and VSA performed the experiments. VSA and LHSQ analyzed the data and VSA wrote the paper.

\section{Conflict of interests}

The authors have declared that in the conflict interests exist.

\section{References}

1. Prado M, Silva MB, Laurenti R, Travassos LR, Taborda CP (2009). Mortality due to systemic mycoses as a primary cause of death or in association with AIDS in Brazil: a review from 1996 to 2006. Mem Inst Oswaldo Cruz 104: 513-521. [Crossref]

2. Marques SA (2013) Paracoccidioidomycosis: epidemiological, clinical, diagnostic and treatment up-dating. An Bras Dermatol 88: 700-711. [Crossref]

3. Teixeira Mde M, Theodoro RC, Oliveira FF, Machado GC, Hahn RC, et al. (2014) Paracoccidioides lutzii sp. nov.: biological and clinical implications. Med Mycol 52: 19-28. [Crossref]

4. Bocca AL, Amaral AC, Teixeira MM, Sato PK, Shikanai-Yasuda MA, et al. (2013) Paracoccidioidomycosis: eco-epidemiology, taxonomy and clinical and therapeutic issues. Future Microbiol 8: 1177-1191. [Crossref]

5. Brummer E, Castaneda E, Restrepo A (1993) Paracoccidioidomycosis: an update. Clin Microbiol Rev 6: 89-117. [Crossref]

6. Restrepo A, McEwen JG, Castaneda E (2001) The habitat of Paracoccidioides brasiliensis: how far from solving the riddle? Med Mycol 39: 233-241. [Crossref]

7. Nemecek JC, Wuthrich M, Klein BS (2006) Global control of dimorphism and virulence in fungi. Science 312: 583-588. [Crossref]

8. Rappleye CA, Goldman WE (2006) Defining virulence genes in the dimorphic fungi. Annu Rev Microbiol 60: 281-303. [Crossref]

9. San-Blas G, Nino-Vega G, Iturriaga T (2002) Paracoccidioides brasiliensis and paracoccidioidomycosis: molecular approaches to morphogenesis, diagnosis, epidemiology, taxonomy and genetics. Med Mycol. 40: 225-242. [Crossref]

10. Kanetsuna F, Carbonell LM, Azuma I, Yamamura Y (1972) Biochemical studies on the thermal dimorphism of Paracoccidioides brasiliensis. J Bacteriol 110: 208-218. [Crossref]

11. Boyce KJ, Andrianopoulos A (2015) Fungal dimorphism: the switch from hyphae to yeast is a specialized morphogenetic adaptation allowing colonization of a host. FEMS Microbiol Rev 39: 797-811. [Crossref]

12. Klein BS, Tebbets B (2007) Dimorphism and virulence in fungi. Curr Opin Microbiol 10: 314-319. [Crossref]

13. Northrop FD, Ljubojevic S, Davies JM (1997) Influence of $\mathrm{Na}^{+}$and anions on the dimorphic transition of Candida albicans. Microbiology 143: 3757-3765. [Crossref]

14. Cano MI, de Aguiar MS (1991) [Utilization of aminoacids in the study of the growth of Paracoccidioides brasiliensis. Influence on dimorphism]. Rev Inst Med Trop Sao Paulo 33: 319-324. [Crossref]

Copyright: $\odot 2018$ Queiroz LHS. This is an open-access article distributed under the terms of the Creative Commons Attribution License, which permits unrestricted use, distribution, and reproduction in any medium, provided the original author and source are credited. 